\title{
Iterative Strain-Gage Balance Calibration Data Analysis for Extended Independent Variable Sets
}

\author{
N. Ulbrich* \\ Jacobs Technology Inc., Moffett Field, California 94035-1000
}

\begin{abstract}
A new method was developed that makes it possible to use an extended set of independent calibration variables for an iterative analysis of wind tunnel strain-gage balance calibration data. The new method permits the application of the iterative analysis method whenever the total number of balance loads and other independent calibration variables is greater than the total number of measured strain-gage outputs. Iteration equations used by the iterative analysis method have the limitation that the number of independent and dependent variables must match. The new method circumvents this limitation. It simply adds a missing dependent variable to the original data set by using an additional independent variable also as an additional dependent variable. Then, the desired solution of the regression analysis problem can be obtained that fits each gage output as a function of both the original and additional independent calibration variables. The final regression coefficients can be converted to data reduction matrix coefficients because the missing dependent variables were added to the data set without changing the regression analysis result for each gage output. Therefore, the new method still supports the application of the two load iteration equation choices that the iterative method traditionally uses for the prediction of balance loads during a wind tunnel test. An example is discussed in the paper that illustrates the application of the new method to a realistic simulation of temperature dependent calibration data set of a six-component balance.
\end{abstract}

\section{Nomenclature}

$\begin{array}{lll}A X & =\text { axial force (independent variable) } \\ \mathbf{B}_{1} & =\text { square matrix used by alternate load iteration equation (see also Ref. [4], p. 12) } \\ \mathbf{C}_{1} & \text { square matrix used by primary load iteration equation (see also Ref. [4], p. 12) } \\ c_{0}, c_{1}, \cdots, c_{m} & =\text { regression coefficients based on original independent variable set } \\ c_{0}, c_{1}, \cdots, c_{n} & =\text { regression coefficients based on extended independent variable set } \\ G_{1}, G_{2}, \cdots, G_{p} & =\text { original dependent variable set (e.g., gage outputs) } \\ i & & =\text { index of original independent/dependent variable } \\ j & & \text { index of additional independent/dependent variable } \\ L_{1}, L_{2}, \cdots, L_{p} & & =\text { original independent variable set (e.g., balance forces and moments) } \\ m & & \text { number of coefficients (excluding intercept) of original independent variable set } \\ n & & \text { number of coefficients (excluding intercept) of extended independent variable set } \\ N & & \text { number of coefficients (including intercept) of extended independent variable set } \\ N 1 & & \text { normal force at forward gage location (independent variable) } \\ N 2 & & \text { normal force at aft gage location (independent variable) } \\ p & =\text { number of original independent/dependent variables } \\ q & =\text { strain-gage outputs (dependent variables) } \\ R 1, R 2, \cdots, R 6 & =\text { rolling moment (independent variable) } \\ R M & \end{array}$

* Aerodynamicist, Jacobs Technology Inc. 
$S$

$\Lambda_{1}, \Lambda_{2}, \cdots, \Lambda_{q}=$ additional independent variable set (e.g., bellows pressures, calibration temperatures)

$=p+q$; sum of the number of original and additional independent variables

$=$ side force at forward gage location (independent variable)

$=$ side force at aft gage location (independent variable)

$=$ assumed balance calibration temperature (additional independent/dependent variable)

\section{Introduction}

In general, a mathematical representation of the calibration data of a wind tunnel strain-gage balance has to be found so that balance loads can be computed from measured strain-gage outputs during a wind tunnel test. This mathematical representation results from performing a global regression analysis of the balance calibration data set.

Two different types of analysis methods are used in the wind tunnel testing community in order perform a global regression analysis of balance calibration data. They are called the iterative method and the non-iterative method (see Ref. [1] for a discussion of the two approaches). Many analysts prefer to use the iterative method. This approach considers the balance loads to be the independent variables and the strain-gage outputs to be the dependent variables of the global regression analysis problem. A more detailed discussion of the iterative method and different iteration equations that are traditionally used in the wind tunnel testing community can be found in Refs. [2], [3], and [4]. Assuming the iterative method is used for the regression analysis, we can write:

$$
\begin{aligned}
& \text { Independent Variables } \Longrightarrow \underbrace{L_{1}, L_{2}, L_{3}, \cdots \cdots, L_{p}}_{\text {original independent variables }} \\
& \text { Dependent Variables } \Longrightarrow \underbrace{G_{1}, G_{2}, G_{3}, \cdots \cdots, G_{p}}_{\text {original dependent variables }}
\end{aligned}
$$

where $L_{1}, \cdots, L_{p}$ are the balance loads, $G_{1}, \cdots, G_{p}$ are the measured gage outputs, and $p$ is the original number of independent (dependent) variables.

The iterative method analyzes calibration data in several steps. First, gage outputs are fitted as a function of the balance loads. The corresponding regression model of the gage outputs has the following form:

$$
G_{i}=\underbrace{c_{0}(i)}_{\text {intercept term }}+\underbrace{c_{1}(i) \cdot L_{1}+\cdots+c_{p}(i) \cdot L_{p}}_{\text {linear terms }}+\underbrace{c_{p+1}(i) \cdot\left|L_{1}\right|+\cdots+c_{m}(i) \cdot\left|L_{p}^{3}\right|}_{\text {absolute value \& non-linear terms }}
$$

The iterative method is often applied to a six-component balance. Then, the regression model defined in Eq. (1) will have 97 possible terms assuming that the intercept and all 10 function classes (math term groups) defined in Ref. [2] are considered.

In the next step, after the coefficients of the analyst's chosen regression model have been computed using a global regression analysis approach, data reduction matrix coefficients are derived from these regression coefficients. Finally, these data reduction matrix coefficients are used in an iteration scheme so that balance loads can be predicted from measured strain-gage outputs during a wind tunnel test (see Refs. [3] and [4] for a detailed description of the two types of load iteration schemes that are used in the industry today).

It is important to remember that the two load iteration equation choices of the iterative method have a common limitation that makes it difficult to directly include independent calibration variables like bellows pressure of air balances or calibration temperatures in the global regression analysis of the strain-gage outputs. This limitation may be summarized as follows:

\section{- LIMITATION OF LOAD ITERATION EQUATION CHOICES - The number of independent variables (applied balance loads) must exactly match the number of dependent variables (measured strain-gage outputs).}


The limitation guarantees that (i) the inverse of matrix $\mathbf{C}_{1}$ used by the primary load iteration equation, and, (ii) the inverse of matrix $\mathbf{B}_{1}$ used by the alternate load iteration equation can be computed (see Ref. [4], Eqs. (28) and (29), for a precise definition of the primary and alternate load iteration equations that may be used with the iterative method).

Sometimes, the number of independent balance calibration variables is greater than the number of dependent variables as strain-gage outputs may not exclusively be a function of balance loads. A sixcomponent air balance is a typical example for this situation. Two bellows pressures may be applied during the calibration in addition to the six balance loads. Consequently, the number of independent calibration variables is eight as each gage output depends on six balance loads and two bellows pressures. The total number of gage outputs, however, remains six. Therefore, a question arises:

\section{- QUESTION -}

Is it somehow possible to apply the iterative method if the total number of independent variables (balance loads plus additional independent variables) is greater than the number of dependent variables (measured strain-gage outputs)?

The answer to the question is "yes." A new method was developed by the author in 2009 that circumvents the limitation of the two load iteration equation choices. Key ideas of the new method will be discussed in the next section of the paper. Then, a simulated calibration data set is used in order to illustrate the application of the new method to a realistic balance calibration data set.

\section{Description of New Method}

The new method was designed to circumvent the limitation of the load iteration equation choices that was discussed above. It simply adds missing dependent variables to the given calibration data set by using the additional independent calibration variables also as additional dependent variables. Then, the desired regression model of the individual gage outputs can be obtained that uses all independent calibration variables, i.e., the original balance loads plus the additional independent variables, to describe the observed physical behavior of the gage outputs.

The new method's approach may be better understood if both independent and dependent variables and the corresponding regression models are expressed mathematically. We know that the set of independent variables, i.e., the balance loads $\left(L_{1}, \cdots, L_{p}\right)$ plus all additional independent variables $\left(\Lambda_{1}, \cdots, \Lambda_{q}\right)$, may be written as follows:

$$
\text { Independent Variables } \Longrightarrow \underbrace{L_{1}, L_{2}, L_{3}, \cdots \cdots, L_{p}}_{\text {original independent variables }}, \underbrace{\Lambda_{1}, \Lambda_{2}, \Lambda_{3}, \cdots \cdots, \Lambda_{q}}_{\text {additional independent variables }}
$$

where $p$ is the number of loads, i.e., the number of original independent variables, and $q$ is the number of additional independent variables. Now, after considering the additional independent variables $\left(\Lambda_{1}, \cdots, \Lambda_{q}\right)$ also to be additional dependent variables, we can list the dependent variables as follows:

$$
\text { Dependent Variables } \Longrightarrow \underbrace{G_{1}, G_{2}, G_{3}, \cdots \cdots, G_{p}}_{\text {original dependent variables }}, \underbrace{\Lambda_{1}, \Lambda_{2}, \Lambda_{3}, \cdots \cdots, \Lambda_{q}}_{\text {additional dependent variables }}
$$

The extended list of independent and dependent variables will make it possible to assemble the linear equation set that is needed to develop an iterative method solution from the calibration data set. The linear equation describing the gage outputs as a function of the independent variables, i.e., as a function of balance loads and additional independent variables, is simply given by the equation:

$$
\begin{aligned}
G_{i}=\underbrace{c_{0}(i)}_{\text {intercept term }}+\underbrace{c_{1}(i) \cdot L_{1}+\cdots+c_{p}(i) \cdot L_{p}}_{\text {linear terms }}+\underbrace{c_{p+1}(i) \cdot \Lambda_{1}+\cdots+c_{p+q}(i) \cdot \Lambda_{q}}_{\text {additional independent variables }} \\
+\underbrace{c_{p+q+1}(i) \cdot\left|L_{1}\right|+\cdots+c_{n}(i) \cdot\left|\Lambda_{q}^{3}\right|}_{\text {absolute value \& non-linear terms }}
\end{aligned}
$$


Let us assume, for example, that a single additional independent variable like the calibration temperature is added to a calibration data set of a six-component balance. Then, the regression model terms defined in Eq. (2a) have to be chosen from a list of 161 terms if the intercept and all math term groups defined in Ref. [2] are included. Ultimately, Eq. (2a) leads to a regression problem solution that fits the individual gage outputs as a function of all independent variables. The final result of this least squares fit is given by the regression coefficient values $c_{0}, c_{1}, \cdots, c_{n}$.

The reader must remember that the linear equation of each of the additional dependent variables is very simple. It is given as follows:

$$
\Lambda_{j}(\text { dep. })=\underbrace{0+0 \cdot L_{1}+\cdots+0 \cdot \Lambda_{j-1}+1 \cdot \Lambda_{j}(\text { indep. })+0 \cdot \Lambda_{j+1}+\cdots+0 \cdot\left|L_{1}\right|+\cdots+0 \cdot\left|\Lambda_{q}^{3}\right|}_{\text {intercept, linear terms, additional independent variables, absolute value \& non-linear terms }}
$$

In other words, the coefficients of the regression model of an additional dependent variable are already known based on theoretical considerations. They are not computed using a least squares fit. Equation (2b) shows that all coefficients of an additional dependent variable must be zero with the exception of the coefficient of the additional independent variable that is identical to the additional dependent variable (see also red oval in Eq. $(2 b))$. This coefficient must have a value of one.

In the next section of the paper a simulated balance calibration data set is used to demonstrate the application of the new method to an extended independent variable set.

\section{Discussion of Example}

\section{A. Balance Calibration Data Simulation}

For the present study the author decided to use calibration data of a six-component balance in order to prepare a simulated data set that could be used to demonstrate the application of the new method. Manual calibration data of NASA's MC60D balance was selected for the simulation as the manufacturer of the balance (Triumph/Force Measurement Systems) supplied temperature senitivities of the six balance gages that could be used to construct a temperature dependent calibration data set.

The MC60D balance is shown in Fig. 1. Table 1 below summarizes important features of the balance and the calibration data set that was used for the present study.

Table 1: Balance and calibration data set characteristics of the MC60D balance.

\begin{tabular}{|c|c|}
\hline CHARACTERISTIC & DESCRIPTION \\
\hline \hline BALANCE TYPE & force balance \\
\hline DIAMETER & $2.0[\mathrm{in}]$ \\
\hline EXCITATION VOLTAGE & $6.0[\mathrm{~V}]$ \\
\hline CALIBRATION DATE & December 2008 \\
\hline CALIBRATION METHOD & manual calibration \\
\hline NUMBER OF ORIGINAL CALIBRATION POINTS & 175 \\
\hline
\end{tabular}

Table 2 lists load capacities of the balance:

Table 2: Load capacities of the MC60D balance.

\begin{tabular}{|l|c|c|c|c|c|c|}
\hline & $N 1, \mathrm{lbs}$ & $N 2, \mathrm{lbs}$ & $S 1, \mathrm{lbs}$ & $S 2, \mathrm{lbs}$ & $R M$, in-lbs & $A X, \mathrm{lbs}$ \\
\hline CAPACITY & 2500 & 2500 & 1250 & 1250 & 5000 & 700 \\
\hline
\end{tabular}

The balance was originally calibrated using a manual calibration approach. A total of 175 calibration points were recorded in 17 load series. The temperature was kept constant during the entire calibration. For 
the present study it was assumed that the original calibration data (i.e., load series 1 to 17) was recorded at a nominal temperature of $70[\mathrm{degF}]$. Then, temperature sensitivity information of the balance manufacturer was used to simulate gage outputs at $110[\mathrm{degF}]$ and $150[\mathrm{degF}]$. Consequently, an additional 350 calibration points were obtained (i.e., load series 18 to 51) that were added to the original calibration data set (i.e., load series 1 to 17). The simulated gage outputs at the two additional temperature levels were obtained by applying a linear extrapolation to the gage outputs that were measured at the nominal temperature of $70[\mathrm{degF}]$. The extrapolation was performed using the following relationship:

$$
G_{i}(T)=G_{i}(70[\operatorname{deg} F])+\frac{\partial G_{i}}{\partial T} \cdot(T-70[\operatorname{deg} F])
$$

where $\partial G_{i} / \partial T$ is the manufacturer supplied temperature sensitivity of the strain-gage with the index $i$. The loads for the simulated additional two data sets, on the other hand, were assumed to be identical with the loads that were used at the nominal calibration temperature of 70 [degF].

Table 3 below summarizes important assumptions that were used to simulate the influence of temperature changes on the original calibration data.

Table 3: Assumed calibration temperature, loads, and gage outputs of different load series ranges.

\begin{tabular}{|c|c|c|c|c|c|}
\hline $\begin{array}{c}\text { SERIES } \\
\text { RANGE }\end{array}$ & $\begin{array}{c}\text { NUMBER OF } \\
\text { POINTS }\end{array}$ & $\begin{array}{c}\text { ASSUMED } \\
\text { TEMPERATURE }\end{array}$ & LOADS & GAGE OUTPUTS & REMARKS \\
\hline \hline 1 to 17 & 175 & $70[\mathrm{degF}]$ & as applied & as measured & supplied by Triumph/FMS \\
\hline 18 to 34 & 175 & $110[\mathrm{degF}]$ & as applied & extrapolated & simulated data \\
\hline 35 to 51 & 175 & $150[\mathrm{degF}]$ & as applied & extrapolated & simulated data \\
\hline
\end{tabular}

Table 4 lists temperature sensitivities of the six gages of the MC60D balance that were used to compute simulated gage outputs after applying the linear extrapolation relationship that is defined in Eq. (3).

Table 4: Temperature sensitivities of strain-gages of the MC60D balance.

\begin{tabular}{|c|c|c|c|}
\hline $\begin{array}{c}\text { GAGE } \\
\text { INDEX }\end{array}$ & $\begin{array}{c}\text { GAGE } \\
\text { OUTPUT }\end{array}$ & $\begin{array}{c}\partial G_{i} / \partial T,[\mathrm{milliV}] /[\mathrm{degF}] \\
\text { (supplied by Triumph/FMS) }\end{array}$ & $\begin{array}{c}\partial G_{i} / \partial T,[\text { microV/V]/[degF }] \\
\text { (converted) }\end{array}$ \\
\hline \hline 1 & $R 1$ & -0.000007 & -0.00117 \\
\hline 2 & $R 2$ & -0.000140 & -0.02333 \\
\hline 3 & $R 3$ & +0.000091 & +0.01517 \\
\hline 4 & $R 4$ & +0.000074 & +0.01233 \\
\hline 5 & $R 5$ & +0.000123 & +0.02050 \\
\hline 6 & $R 6$ & -0.000070 & -0.01166 \\
\hline
\end{tabular}

Figure 2 shows parts of the final calibration data input file that was used for the present study. The original data (subset 1, 175 data points) and the two simulated data sets (subsets $2 \& 3,350$ data points) of the calibration data are depicted. In addition, the independent and dependent variables of the calibration data set are marked. The calibration temperature was introduced as the 7 th independent/dependent variable of the simulated calibration data set. Blue ovals in Fig. 2 illustrate the simulated temperature influence on the gage outputs of three data points. These three data points experienced identical loadings that are highlighted by green ovals.

Figure 3a shows the applied calibration loads for both the original and simulated data subsets. They are the original independent variables of the global regression problem. Figure $3 \mathrm{~b}$ shows the measured and simulated gage outputs for both the original and simulated data subsets. They are the dependent variables of the global regression problem.

In the next section of the paper the application of a candidate math model search algorithm to the simulated data set is discussed. The candidate math model search provided optimized regression models of 
the six strain-gage outputs that met strict statistical quality requirements. They were used for the final regression analysis of the simulated data set using the iterative method.

\section{B. Candidate Math Model Search}

During the past six years a candidate math model search algorithm was developed at Ames Research Center that identifies optimized regression models of multivariate experimental data sets (see Refs. [1], [5], and [6] for a description of different aspects of the algorithm). The algorithm was implemented in NASA's regression analysis tool BALFIT and has been applied to the simulated data set that was described in the previous section. The final result of the candidate math model search depends on the experimental data set and the combination of search parameter that the user may choose in BALFIT's user interface. Table 5 below lists the settings that were chosen for the candidate math model search.

Table 5: Candidate math model search parameter selections.

\begin{tabular}{|c|c|}
\hline CANDIDATE MATH MODEL SEARCH PARAMETER & SELECTION \\
\hline \hline MATH TERM GROUP COMBINATION & $x, x^{2}, x y$ \\
\hline INTERCEPT & included \\
\hline TARE LOAD CORRECTION & not required \\
\hline SEARCH CONSTRAINT 1: HIERARCHY RULE & applied during search \\
\hline SEARCH CONSTRAINT 2: VARIANCE INFLATION FACTOR MAXIMUM & $<10$ \\
\hline SEARCH CONSTRAINT 3: P-VALUE OF T-STATISTIC MAXIMUM & $<0.001$ \\
\hline SEARCH STRATEGY (defined in Ref. [1], p. 5) & forward selection \\
\hline IDENTIFICATION METRIC (defined in Ref. [1], p. 5) & search metric minimum \\
\hline
\end{tabular}

Figure 4 depicts the candidate math model search metric versus the number of candidate math model terms. The search metric was minimized during the math model search. The blue symbols in Fig. 4 mark the search metric value of the recommended math model of each of the six balance gages.

Figure 5 depicts terms of the recommended math model of the balance gages $R 1$ to $R 6$. The recommended math model of the calibration temperature $T($ dep.), i.e., of the additional dependent variable, is also shown. These seven math models were used for the final regression analysis of the simulated balance calibration data set. Three observations can be made if the term selection given in Fig. 5 is analyzed:

Observation 1: The candidate math model search recommended to only use the linear term of the calibration temperature $T$ (indep.). This result is expected because the simulated data was generated using a linear relationship between the calibration temperature change and the electrical outputs of the gages. This linear relationship was "hidden" in the simulated strain-gage outputs.

Observation 2: The candidate math model search concluded that the first gage output $R 1$ is independent of the calibration temperature (see also red ovals in Fig. 5). This result can be understood after comparing the temperature sensitivities that were used to simulated the gage outputs at different temperature levels (see Table 4). Comparing the temperature sensitivities we conclude that the temperature sensitivity of the first gage output $R 1$ is one order of magnitude smaller than the temperature sensitivity of the remaining five gages. Therefore, the optimization algorithm correctly predicted that the temperature sensitivity of the first gage output $R 1$ is negligible if compared with the temperature sensitivity of the remaining five gages.

Observation 3: The recommended math model of the calibration temperature $T(d e p$.$) , i.e., of the ad-$ ditional 7th dependent variable of the simulated calibration data set, is exclusively a function of the corresponding matching independent variable T(indep.) (see also blue ovals in Fig. 5). This result is expected as, by design, each value of $T$ (indep.) exactly matches each value of $T(d e p$.). Therefore, the coefficients of all other terms of the regression model of $T(d e p$.$) must be zero.$

In the next section of the paper the final analysis results of the application of the recommended math models to the simulated data set are discussed in more detail. 


\section{Iterative Data Analysis Results}

Recommended math models shown in Fig. 5 were used to perform the final analysis of the simulated data set. First, least squares solutions of the regression models of the seven dependent variables, i.e., $R 1$, $\cdots, R 6, T(d e p$.), were obtained. Corresponding regression coefficients are listed in Fig. 6 . The total number of possible regression coefficients $(N)$ is 127 as the total number of independent variables $(s)$ is 7 . The total number of regression coefficients for other values of the total number of original and additional independent variables is given by the following formula:

$$
N=1+2 \cdot s \cdot(s+2)
$$

Only 50 of 127 coefficient rows of the regression coefficient matrix are shown in Fig. 6. Coefficient values of term $T$ (indep.) of all dependent variables are highlighted in red color in Fig. 6 and listed in Table 6.

Table 6: Coefficient values of regression model term $T$ (indep.).

\begin{tabular}{|c|c|c|}
\hline DEP. VARIABLE & COEFFICIENT OF T(indep.) & COMMENTS \\
\hline \hline$R 1$ & 0 & not used \\
\hline$R 2$ & -0.02333 & least squares fit result \\
\hline$R 3$ & +0.01517 & least squares fit result \\
\hline$R 4$ & +0.01233 & least squares fit result \\
\hline$R 5$ & +0.02050 & least squares fit result \\
\hline$R 6$ & -0.01166 & least squares fit result \\
\hline$T(d e p)$. & 1.0 & automatically assigned \\
\hline
\end{tabular}

Comparing numerical values listed in the second column of Table 6 with temperature sensitivities listed in the last column of Table 4 we see that they show excellent agreement. This result can be better understood after revisiting Eq. (3) that was used to simulate temperature effects in the extended calibration data set. Equation (3) may also be written as follows:

$$
G_{i}(T(\text { indep. }))=\underbrace{\left[G_{i}(70[\operatorname{deg} F])-\frac{\partial G_{i}}{\partial T} \cdot 70[\operatorname{deg} F]\right]}_{\text {constant term, contained in intercept }}+\underbrace{\left[\frac{\partial G_{i}}{\partial T}\right]}_{\text {coefficient }} \cdot T(\text { indep. })
$$

The linear relationship between gage outputs and calibration temperature change was intentionally enforced when the simulated gage outputs of load series 18 to 51 were generated using Eq. (3). Equation (5), i.e., the alternate form of Eq. (3), shows that the simulation added a constant and a temperature dependent term to the original gage outputs. The constant term is absorbed in the intercept term after the completion of the least squares fit. The first derivative of the temperature dependent term, on the other hand, becomes the coefficient of regression model term $T$ (indep.).

Figure 7 shows the data reduction matrix coefficients that were obtained from the regression coefficients depicted in Fig. 6. Again, only 50 of the 127 coefficient rows are shown. Finally, the data reduction matrix coefficients listed in Fig. 7 were used in combination with the primary load iteration equation in order to compute the fitted calibration loads of the 525 data points of the simulated balance calibration data set. The corresponding load residuals of the six balance load components, i.e., the differences between fitted and applied calibration load, are shown in Fig. 8. The residuals are small and well within the $0.25 \%$ threshold that is used at Ames as a load residuals quality metric.

\section{Summary and Conclusions}

A new method was presented that makes it possible to use the iterative method in combination with an extended set of independent calibration variables for the regression analysis of wind tunnel strain-gage 
balance calibration data. The extended set of independent variables consists of balance loads and additional independent variables that influence electrical outputs of strain-gages. Additional independent variables could be, for example, bellows pressures of an air balance, or, a calibration temperature. A simulation of a temperature dependent calibration data set was used to demonstrate the application of the new method.

The new method supports both load iteration equation choices that are used in the wind tunnel testing community. Therefore, the method can easily be implemented in an existing wind tunnel facility that uses the iterative method. Only a few changes need to be made to the analysis software that processes balance calibration data and to the data system software that computes balance loads during a wind tunnel test:

(1) The analysis software must have the ability to process a regression model of strain-gage outputs that is constructed from an extended set of independent variables. Existing software often supports a sixcomponent balance. In that case, the analysis software must be modified to generate a data reduction matrix that uses, e.g., 7, 8, or more independent calibration variables.

(2) The analysis software must have the ability to automatically identify all additional independent and dependent variables of an extended balance calibration data set.

(3) The analysis software must have the ability to automatically assign, i.e., not compute, coefficients of the regression model of an additional dependent variable. All numerical values of an additional dependent variable must, by design, exactly match all numerical values of one of the additional independent variables. The coefficient of this matching independent variable must be set to one. The coefficients of all other terms of the regression model of the additional dependent variable must be set to zero.

(4) The data system software must have the ability to read and process an extended data reduction matrix format so that balance loads can be predicted during a wind tunnel test from (i) the measured strain-gage outputs and (ii) the measured values of the additional independent variables.

The new method is implemented in NASA's analysis software tool BALFIT. It is also available for use in a production wind tunnel environment as the data system software of Ames' Unitary Plan Wind Tunnel supports the new method. In 2010, the new method was successfully applied to a complex wind tunnel test that used an air balance. This air balance is a modified six-component balance that was calibrated using two bellows pressures as additional independent variables.

\section{Acknowledgements}

The author would like to thank Tom Volden of Jacobs Technology for his critical and constructive review of the final manuscript. The work reported in this paper was partially supported by NASA's Aeronautic Test Program and the Wind Tunnel Division at Ames Research Center under contract NNA09DB39C.

\section{References}

${ }^{1}$ Ulbrich, N., "Comparison of Iterative and Non-Iterative Strain-Gage Balance Load Calculation Methods," AIAA 2010-4202, paper presented at the 27th AIAA Aerodynamic Measurement Technology and Ground Testing Conference, Chicago, Illinois, June/July 2010.

${ }^{2}$ AIAA/GTTC Internal Balance Technology Working Group, "Recommended Practice, Calibration and Use of Internal Strain-Gage Balances with Application to Wind Tunnel Testing," AIAA R-091-2003, American Institute of Aeronautics and Astronautics, Reston, Virginia, 2003, pp. 7-19.

${ }^{3}$ Ulbrich, N. and Volden, T., "Strain-Gage Balance Calibration Analysis Using Automatically Selected Math Models," AIAA 2005-4084, paper presented at the 41st AIAA/ASME/SAE/ASEE Joint Propulsion Conference and Exhibit, Tucson, Arizona, July 2005, pp. 9-14.

${ }^{4}$ Ulbrich, N. and Volden, T., "Application of a New Calibration Analysis Process to the MK-III-C Balance," AIAA 2006-0517, paper presented at the 44th AIAA Aerospace Sciences Meeting and Exhibit, Reno, Nevada, January 2006, pp. 9-12.

${ }^{5}$ Ulbrich, N., "Regression Model Optimization for the Analysis of Experimental Data," AIAA 2009-1344, paper presented at the 47th AIAA Aerospace Sciences Meeting and Exhibit, Orlando, Florida, January 2009.

${ }^{6}$ Ulbrich, N., "Optimization of Regression Models of Experimental Data using Confirmation Points," AIAA 2010-0930, paper presented at the 48th AIAA Aerospace Sciences Meeting and Exhibit, Orlando, Florida, January 2010. 


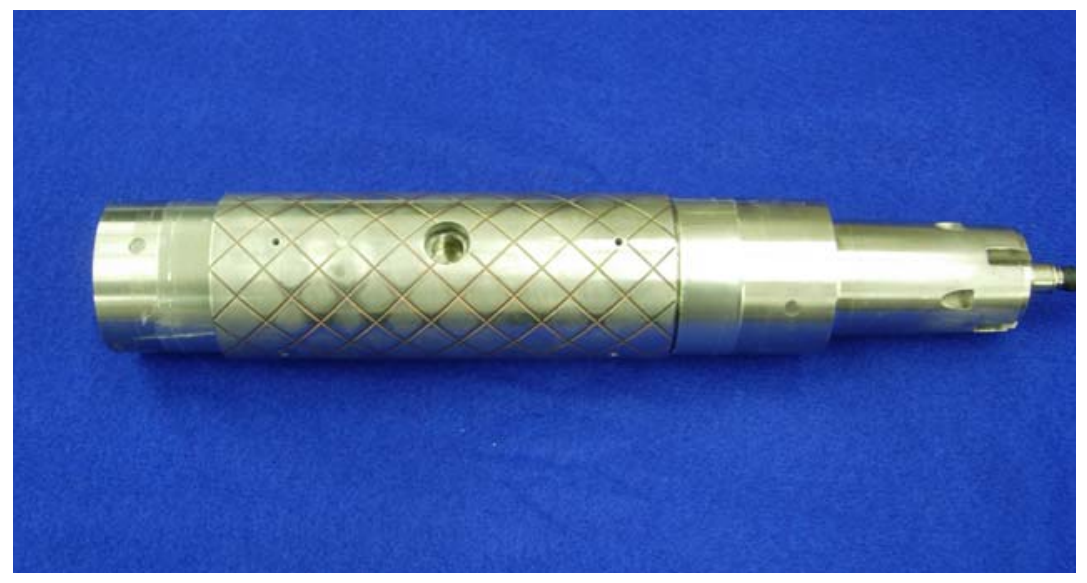

Fig. 1 NASA's MC60D strain-gage balance (photo courtesy of Triumph/FMS).

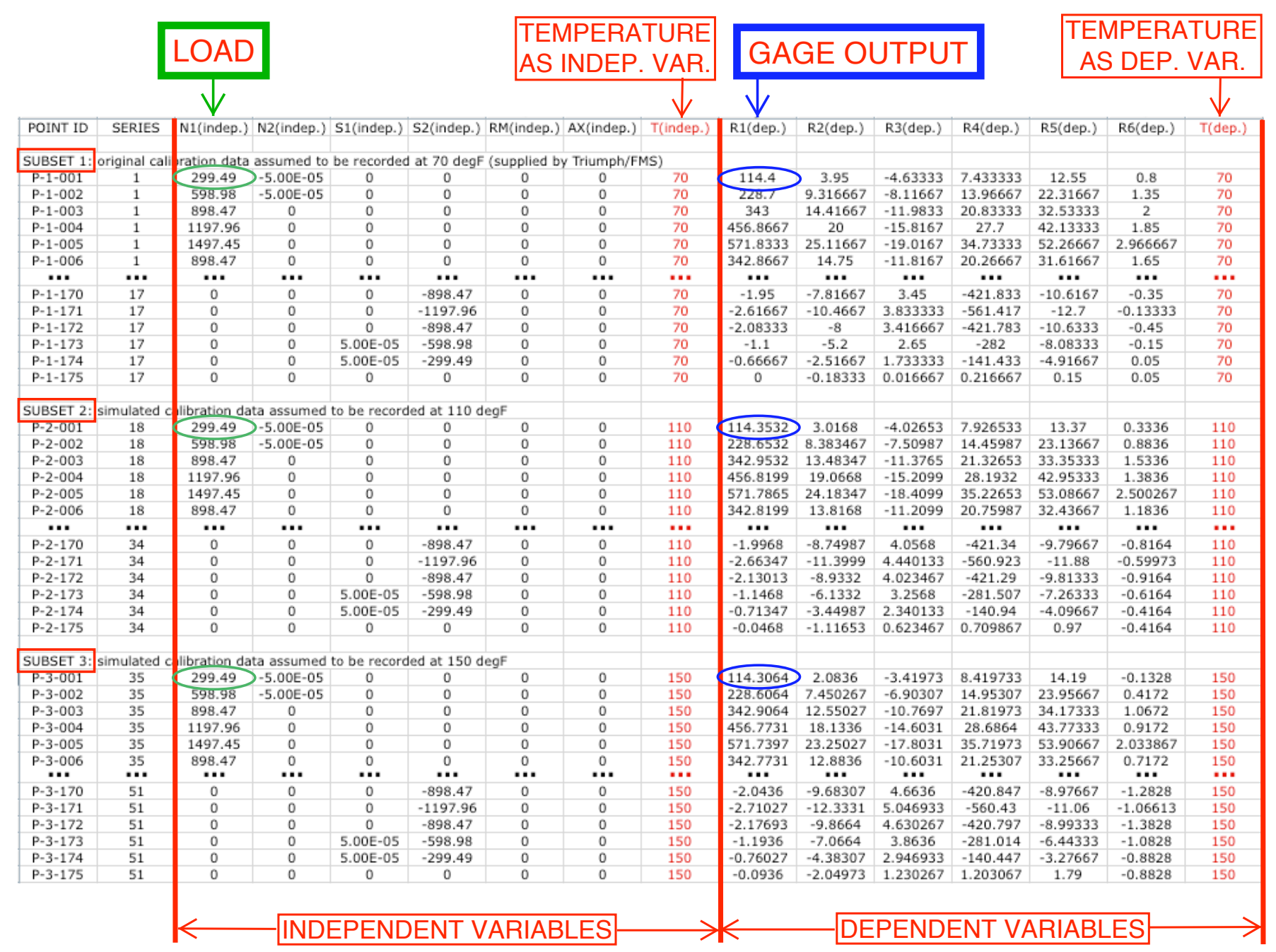

Fig. 2 Balance calibration data input file (original plus simulated data).

American Institute of Aeronautics and Astronautics 

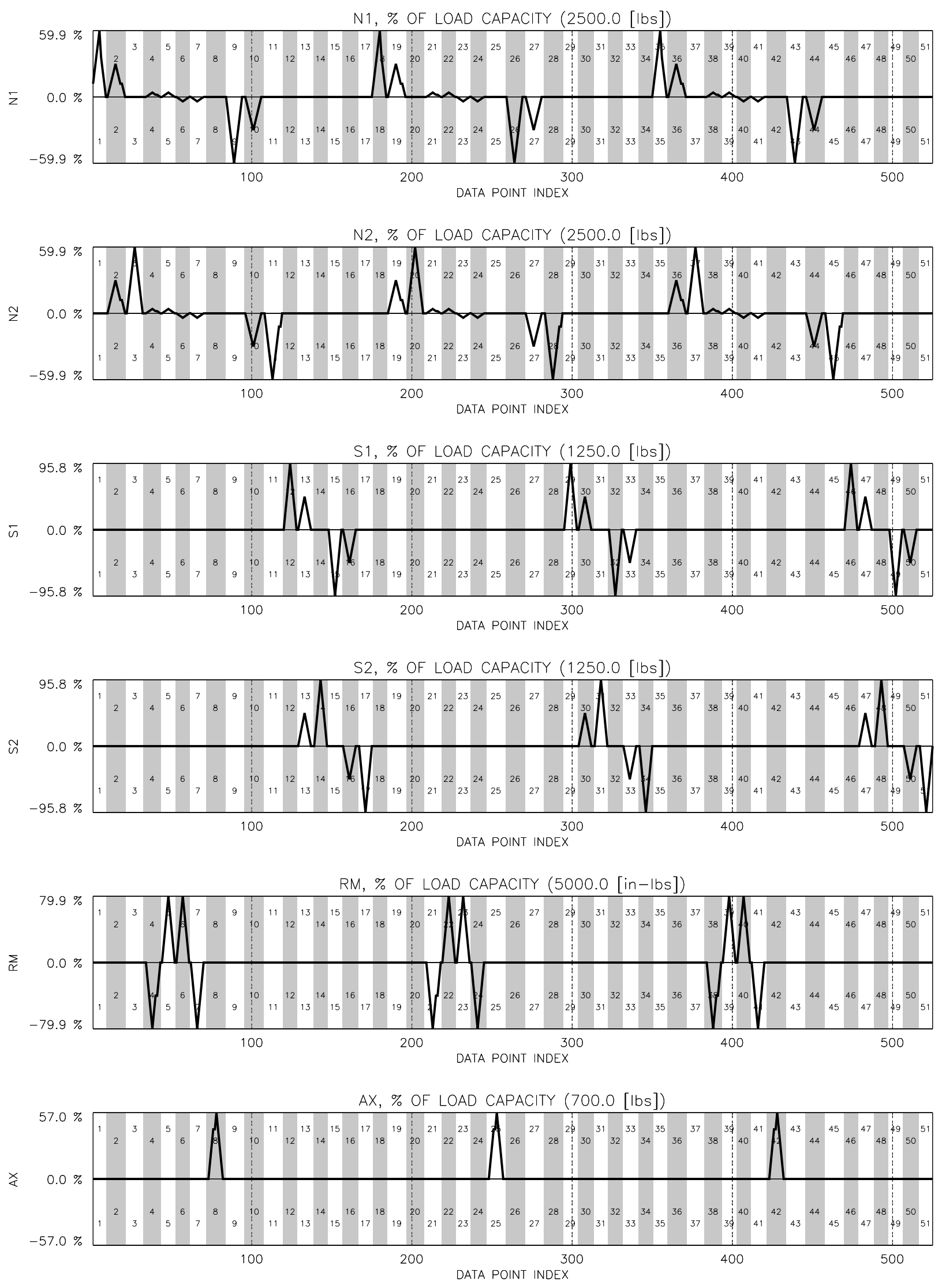

Fig. 3a Original Independent Variables: Balance calibration loads versus data point indices. 
R1, \% OF GAGE OUTPUT CAPACITY (571.83 [microV/V])

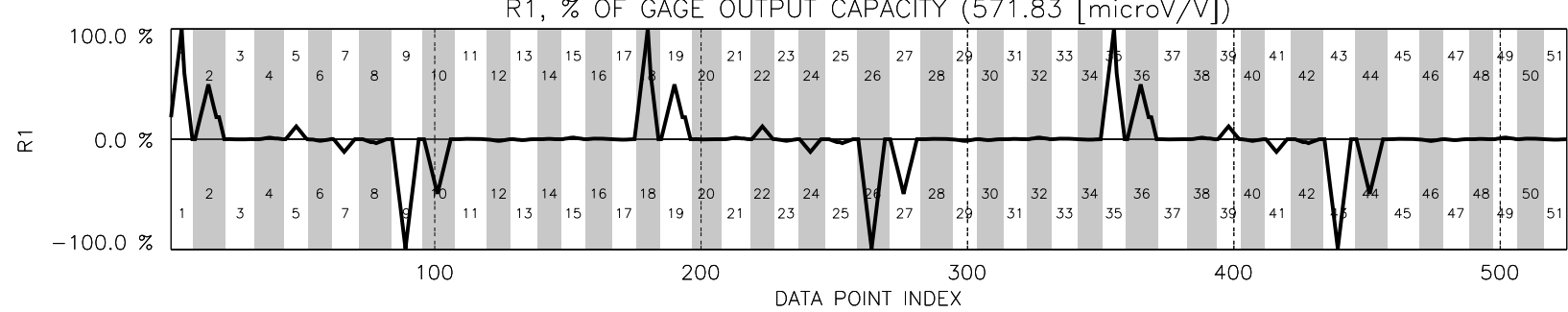

R2, \% OF GAGE OUTPUT CAPACITY (697.97 [microV/V])
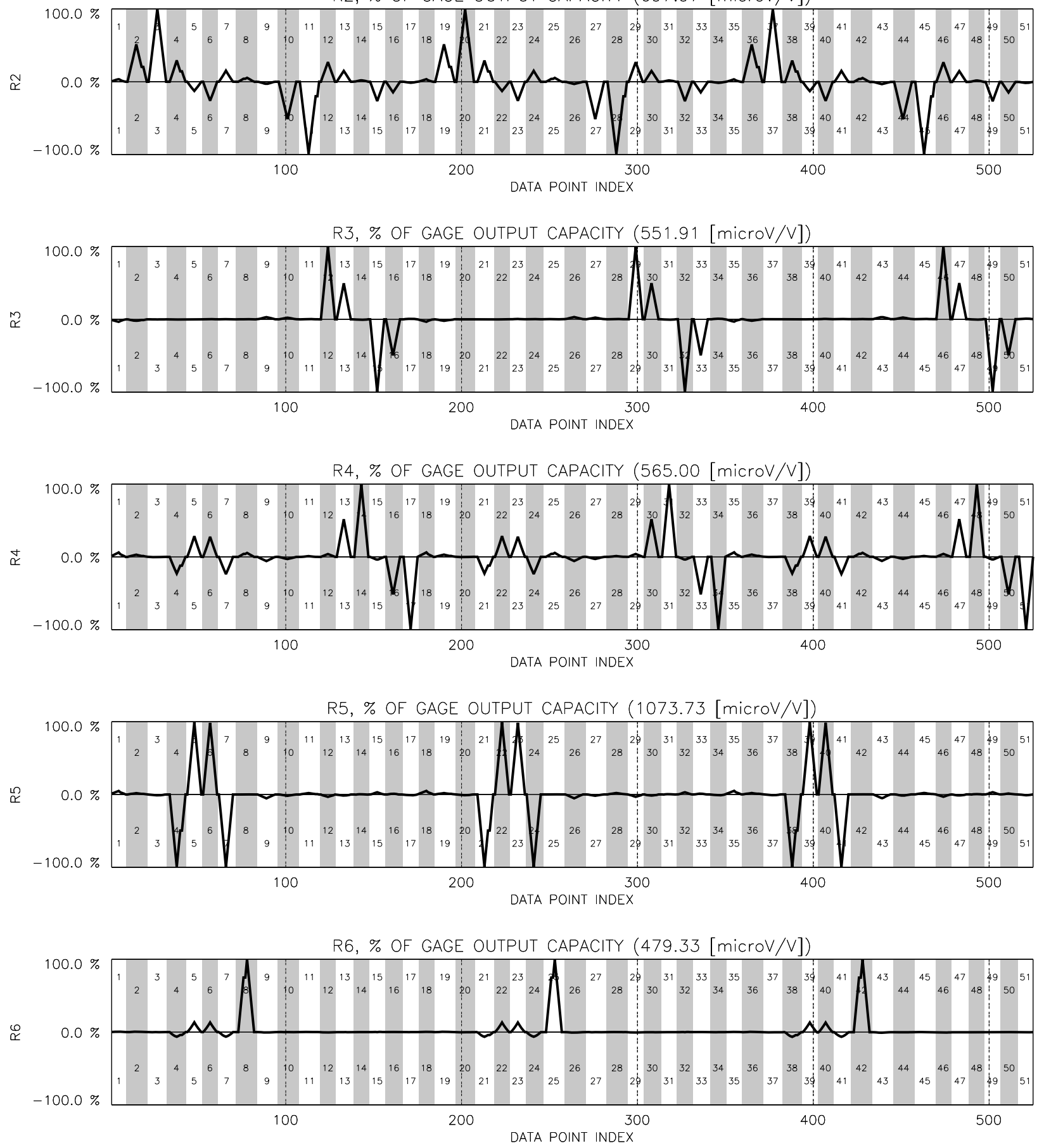

Fig. 3b Original Dependent Variables: Strain-gage outputs versus data point indices.

American Institute of Aeronautics and Astronautics 


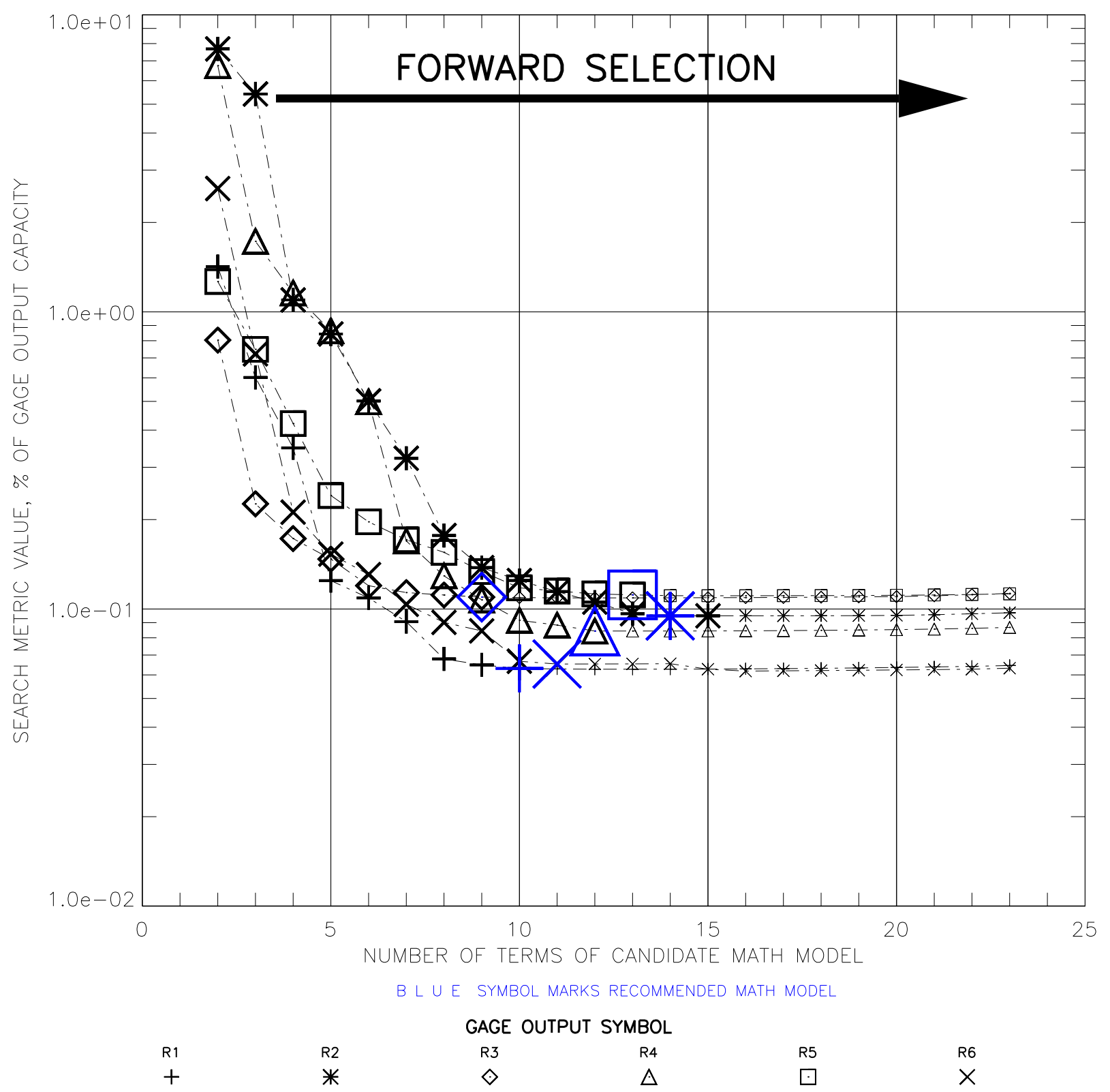

Fig. 4 Candidate math model search metric versus number of math model terms. 


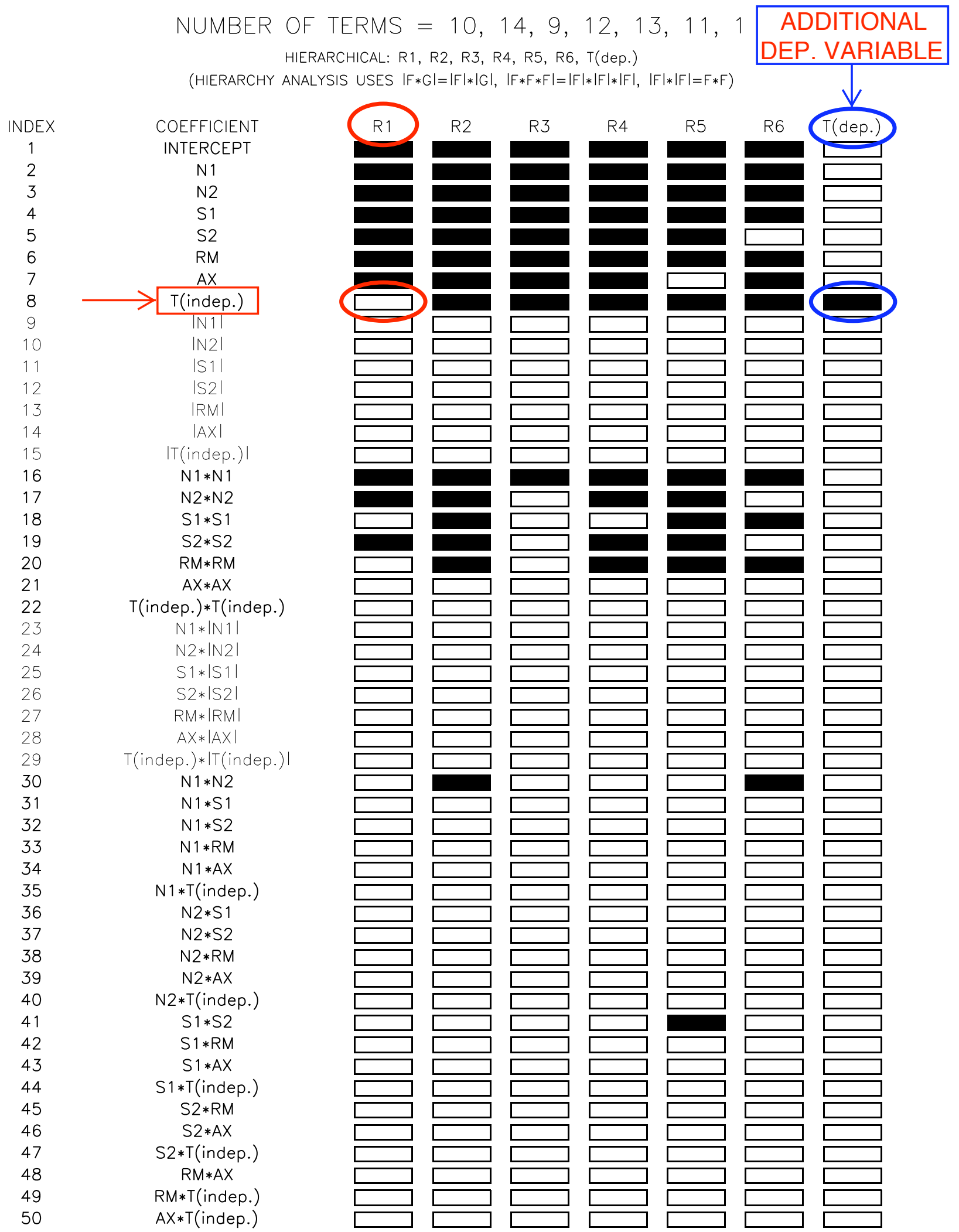

Fig. 5 Recommended math models of all dependent variables (only 50 of 127 coefficient rows are shown). 


\begin{tabular}{|c|c|c|c|c|c|c|c|}
\hline GAGE_OUT_NAME & R1 & R2 & R3 & R4 & R5 & R6 & $\mathrm{T}($ dep. $)$ \\
\hline GAGE_OUT_UNIT & $\mathrm{microV} / \mathrm{V}$ & $\mathrm{microV} / \mathrm{V}$ & $\mathrm{microV} / \mathrm{V}$ & $\mathrm{microV} / \mathrm{V}$ & $\mathrm{microV} / \mathrm{V}$ & $\mathrm{microV} / \mathrm{V}$ & $\operatorname{degF}$ \\
\hline INTERCEPT & $-3.394912 e-02$ & $1.762373 \mathrm{e}+00$ & $-1.054617 e+00$ & $-8.418984 e-01$ & $-1.579497 e+00$ & $8.546633 e-01$ & $0.000000 \mathrm{e}+00$ \\
\hline $\mathrm{N} 1$ & $3.805402 \mathrm{e}-01$ & $1.512768 \mathrm{e}-02$ & $-1.304557 e-02$ & $2.301752 \mathrm{e}-02$ & $3.674621 \mathrm{e}-02$ & $2.279791 \mathrm{e}-03$ & $0.000000 \mathrm{e}+00$ \\
\hline N2 & $-1.064056 e-03$ & $4.636386 \mathrm{e}-01$ & $-1.430480 \mathrm{e}-03$ & $-1.933541 \mathrm{e}-03$ & $-1.136899 e-02$ & $-4.737361 e-04$ & $0.000000 \mathrm{e}+00$ \\
\hline S1 & $-8.113330 \mathrm{e}-03$ & $1.572993 e-01$ & $4.593450 \mathrm{e}-01$ & $1.863997 \mathrm{e}-02$ & $-2.919441 e-02$ & $-1.627261 e-03$ & $0.000000 \mathrm{e}+00$ \\
\hline S2 & $1.482529 \mathrm{e}-03$ & $1.147374 \mathrm{e}-02$ & $-3.444924 e-03$ & $4.701974 \mathrm{e}-01$ & $6.487459 \mathrm{e}-03$ & $0.000000 \mathrm{e}+00$ & $0.000000 \mathrm{e}+00$ \\
\hline $\mathrm{RM}$ & $7.249169 \mathrm{e}-03$ & $-3.641411 e-02$ & $1.193664 \mathrm{e}-04$ & $3.630710 \mathrm{e}-02$ & $2.669301 \mathrm{e}-01$ & $1.185475 \mathrm{e}-02$ & $0.000000 \mathrm{e}+00$ \\
\hline$A X$ & $-5146061 e-02$ & $9471648 e-02$ & $20>1353 e-03$ & $7792126 e-02$ & a ananane+an & $1200520 e+00$ & $a$ ananane+an \\
\hline T(indep.) & $0.000000 \mathrm{e}+00$ & $-2.333000 e-02$ & $1.517000 \mathrm{e}-02$ & $1.233000 \mathrm{e}-02$ & $2.050000 \mathrm{e}-02$ & $-1.166000 \mathrm{e}-02$ & $1.000000 \mathrm{e}+00$ \\
\hline |N1| & $0.000000 \mathrm{e}+00$ & $0.000000++00$ & $0.000000 e+00$ & $0.000000 \mathrm{e}+00$ & $0.000000 \mathrm{e}+00$ & $0.000000 \mathrm{e}+00$ & $0.000000 \mathrm{e}+00$ \\
\hline |N2 | & $0.000000 \mathrm{e}+00$ & $0.000000 \mathrm{e}+00$ & $0.000000 \mathrm{e}+00$ & $0.000000 \mathrm{e}+00$ & $0.000000 \mathrm{e}+00$ & $0.000000 \mathrm{e}+00$ & $0.000000 \mathrm{e}+00$ \\
\hline$|S 1|$ & $0.000000 \mathrm{e}+00$ & $0.000000 \mathrm{e}+00$ & $0.000000 \mathrm{e}+00$ & $0.000000 \mathrm{e}+00$ & $0.000000 \mathrm{e}+00$ & $0.000000 \mathrm{e}+00$ & $0.000000 \mathrm{e}+00$ \\
\hline$|S 2|$ & $0.000000 \mathrm{e}+00$ & $0.000000 \mathrm{e}+00$ & $0.000000 \mathrm{e}+00$ & $0.000000 \mathrm{e}+00$ & $0.000000 \mathrm{e}+00$ & $0.000000 \mathrm{e}+00$ & $0.000000 \mathrm{e}+00$ \\
\hline |RM| & $0.000000 \mathrm{e}+00$ & $0.000000 \mathrm{e}+00$ & $0.000000 \mathrm{e}+00$ & $0.000000 \mathrm{e}+00$ & $0.000000 \mathrm{e}+00$ & $0.000000 \mathrm{e}+00$ & $0.000000 \mathrm{e}+00$ \\
\hline$|A X|$ & $0.000000 \mathrm{e}+00$ & $0.000000 \mathrm{e}+00$ & $0.000000 \mathrm{e}+00$ & $0.000000 \mathrm{e}+00$ & $0.000000 \mathrm{e}+00$ & $0.000000 \mathrm{e}+00$ & $0.000000 \mathrm{e}+00$ \\
\hline $\mid T($ indep.) $\mid$ & $0.000000 \mathrm{e}+00$ & $0.000000 \mathrm{e}+00$ & $0.000000 \mathrm{e}+00$ & $0.000000 \mathrm{e}+00$ & $0.000000 \mathrm{e}+00$ & $0.000000 \mathrm{e}+00$ & $0.000000 \mathrm{e}+00$ \\
\hline $\mathrm{N} 1 * \mathrm{~N} 1$ & $1.033800 \mathrm{e}-06$ & $9.752645 e-07$ & $-6.667183 e-07$ & $4.612807 \mathrm{e}-07$ & $-8.097094 e-07$ & $-2.015103 e-07$ & $0.000000 \mathrm{e}+00$ \\
\hline $\mathrm{N} 2 * \mathrm{~N} 2$ & $3.117077 \mathrm{e}-07$ & $1.497467 \mathrm{e}-06$ & $0.000000 \mathrm{e}+00$ & $9.823289 \mathrm{e}-07$ & $2.325573 e-06$ & $0.000000 \mathrm{e}+00$ & $0.000000 \mathrm{e}+00$ \\
\hline $\mathrm{S} 1 * \mathrm{~S} 1$ & $0.000000 \mathrm{e}+00$ & $1.694179 \mathrm{e}-06$ & $0.000000 \mathrm{e}+00$ & $0.000000 \mathrm{e}+00$ & $-1.423645 e-06$ & $-1.102441 \mathrm{e}-06$ & $0.000000 \mathrm{e}+00$ \\
\hline $\mathrm{S} 2 * \mathrm{~S} 2$ & $-4.339874 e-07$ & $1.908978 \mathrm{e}-06$ & $0.000000 \mathrm{e}+00$ & $7.596264 \mathrm{e}-07$ & $-4.214591 e-06$ & $0.000000 \mathrm{e}+00$ & $0.000000 \mathrm{e}+00$ \\
\hline $\mathrm{RM} * \mathrm{RM}$ & $0.000000 \mathrm{e}+00$ & $6.515069 \mathrm{e}-07$ & $0.000000 \mathrm{e}+00$ & $8.691516 e-07$ & $-2.981815 e-07$ & $1.056434 \mathrm{e}-06$ & $0.000000 \mathrm{e}+00$ \\
\hline$A X * A X$ & $0.000000 \mathrm{e}+00$ & $0.000000 \mathrm{e}+00$ & $0.000000 \mathrm{e}+00$ & $0.000000 \mathrm{e}+00$ & $0.000000 \mathrm{e}+00$ & $0.000000 \mathrm{e}+00$ & $0.000000 \mathrm{e}+00$ \\
\hline $\mathrm{T}($ indep.)*T(indep.) & $0.000000 \mathrm{e}+00$ & $0.000000 \mathrm{e}+00$ & $0.000000 \mathrm{e}+00$ & $0.000000 \mathrm{e}+00$ & $0.000000 \mathrm{e}+00$ & $0.000000 \mathrm{e}+00$ & $0.000000 \mathrm{e}+00$ \\
\hline $\mathrm{N} 1 *|\mathrm{~N} 1|$ & $0.000000 \mathrm{e}+00$ & $0.000000 \mathrm{e}+00$ & $0.000000 \mathrm{e}+00$ & $0.000000 \mathrm{e}+00$ & $0.000000 \mathrm{e}+00$ & $0.000000 \mathrm{e}+00$ & $0.000000 \mathrm{e}+00$ \\
\hline $\mathrm{N} 2 *|\mathrm{~N} 2|$ & $0.000000 \mathrm{e}+00$ & $0.000000 \mathrm{e}+00$ & $0.000000 \mathrm{e}+00$ & $0.000000 \mathrm{e}+00$ & $0.000000 \mathrm{e}+00$ & $0.000000 \mathrm{e}+00$ & $0.000000 \mathrm{e}+00$ \\
\hline$S 1 *|S 1|$ & $0.000000 \mathrm{e}+00$ & $0.000000 \mathrm{e}+00$ & $0.000000 \mathrm{e}+00$ & $0.000000 \mathrm{e}+00$ & $0.000000 \mathrm{e}+00$ & $0.000000 \mathrm{e}+00$ & $0.000000 \mathrm{e}+00$ \\
\hline$S 2 *|S 2|$ & $0.000000 \mathrm{e}+00$ & $0.000000 \mathrm{e}+00$ & $0.000000 \mathrm{e}+00$ & $0.000000 \mathrm{e}+00$ & $0.000000 \mathrm{e}+00$ & $0.000000 \mathrm{e}+00$ & $0.000000 \mathrm{e}+00$ \\
\hline $\mathrm{RM} *|\mathrm{RM}|$ & $0.000000 \mathrm{e}+00$ & $0.000000 \mathrm{e}+00$ & $0.000000 \mathrm{e}+00$ & $0.000000 \mathrm{e}+00$ & $0.000000 \mathrm{e}+00$ & $0.000000 \mathrm{e}+00$ & $0.000000 \mathrm{e}+00$ \\
\hline$A X *|A X|$ & $0.000000 \mathrm{e}+00$ & $0.000000 \mathrm{e}+00$ & $0.000000 \mathrm{e}+00$ & $0.000000 \mathrm{e}+00$ & $0.000000 \mathrm{e}+00$ & $0.000000 \mathrm{e}+00$ & $0.000000 \mathrm{e}+00$ \\
\hline (indep.)*|T(indep.) | & $0.000000 \mathrm{e}+00$ & $0.000000 \mathrm{e}+00$ & $0.000000 \mathrm{e}+00$ & $0.000000 \mathrm{e}+00$ & $0.000000 \mathrm{e}+00$ & $0.000000 \mathrm{e}+00$ & $0.000000 \mathrm{e}+00$ \\
\hline $\mathrm{N} 1 * \mathrm{~N} 2$ & $0.000000 \mathrm{e}+00$ & $-1.509473 e-06$ & $0.000000 \mathrm{e}+00$ & $0.000000 \mathrm{e}+00$ & $0.000000 \mathrm{e}+00$ & $3.050592 \mathrm{e}-06$ & $0.000000 \mathrm{e}+00$ \\
\hline $\mathrm{N} 1 * \mathrm{~S} 1$ & $0.000000 \mathrm{e}+00$ & $0.000000 \mathrm{e}+00$ & $0.000000 \mathrm{e}+00$ & $0.000000 \mathrm{e}+00$ & $0.000000 \mathrm{e}+00$ & $0.000000 \mathrm{e}+00$ & $0.000000 \mathrm{e}+00$ \\
\hline $\mathrm{N} 1 * \mathrm{~S} 2$ & $0.000000 \mathrm{e}+00$ & $0.000000 \mathrm{e}+00$ & $0.000000 \mathrm{e}+00$ & $0.000000 \mathrm{e}+00$ & $0.000000 \mathrm{e}+00$ & $0.000000 \mathrm{e}+00$ & $0.000000 \mathrm{e}+00$ \\
\hline $\mathrm{N} 1 * \mathrm{RM}$ & $0.000000 \mathrm{e}+00$ & $0.000000 \mathrm{e}+00$ & $0.000000 \mathrm{e}+00$ & $0.000000 \mathrm{e}+00$ & $0.000000 \mathrm{e}+00$ & $0.000000 \mathrm{e}+00$ & $0.000000 \mathrm{e}+00$ \\
\hline $\mathrm{N} 1 * \mathrm{AX}$ & $0.000000 \mathrm{e}+00$ & $0.000000 \mathrm{e}+00$ & $0.000000 \mathrm{e}+00$ & $0.000000 \mathrm{e}+00$ & $0.000000 \mathrm{e}+00$ & $0.000000 \mathrm{e}+00$ & $0.000000 \mathrm{e}+00$ \\
\hline N1*T(indep.) & $0.000000 \mathrm{e}+00$ & $0.000000 \mathrm{e}+00$ & $0.000000 \mathrm{e}+00$ & $0.000000 \mathrm{e}+00$ & $0.000000 \mathrm{e}+00$ & $0.000000 \mathrm{e}+00$ & $0.000000 \mathrm{e}+00$ \\
\hline $\mathrm{N} 2 * \mathrm{~S} 1$ & $0.000000 \mathrm{e}+00$ & $0.000000 \mathrm{e}+00$ & $0.000000 e+00$ & $0.000000 \mathrm{e}+00$ & $0.000000 \mathrm{e}+00$ & $0.000000 \mathrm{e}+00$ & $0.000000 \mathrm{e}+00$ \\
\hline $\mathrm{N} 2 * \mathrm{~S} 2$ & $0.000000 \mathrm{e}+00$ & $0.000000 \mathrm{e}+00$ & $0.000000 \mathrm{e}+00$ & $0.000000 \mathrm{e}+00$ & $0.000000 \mathrm{e}+00$ & $0.000000 \mathrm{e}+00$ & $0.000000 \mathrm{e}+00$ \\
\hline $\mathrm{N} 2 * \mathrm{RM}$ & $0.000000 \mathrm{e}+00$ & $0.000000 \mathrm{e}+00$ & $0.000000 \mathrm{e}+00$ & $0.000000 \mathrm{e}+00$ & $0.000000 \mathrm{e}+00$ & $0.000000 \mathrm{e}+00$ & $0.000000 \mathrm{e}+00$ \\
\hline $\mathrm{N} 2 * \mathrm{AX}$ & $0.000000 \mathrm{e}+00$ & $0.000000 \mathrm{e}+00$ & $0.000000 \mathrm{e}+00$ & $0.000000 \mathrm{e}+00$ & $0.000000 \mathrm{e}+00$ & $0.000000 \mathrm{e}+00$ & $0.000000 \mathrm{e}+00$ \\
\hline $\mathrm{N} 2 * \mathrm{~T}$ (indep.) & $0.000000 \mathrm{e}+00$ & $0.000000 \mathrm{e}+00$ & $0.000000 \mathrm{e}+00$ & $0.000000 \mathrm{e}+00$ & $0.000000 \mathrm{e}+00$ & $0.000000 \mathrm{e}+00$ & $0.000000 \mathrm{e}+00$ \\
\hline $\mathrm{S} 1 * \mathrm{~S} 2$ & $0.000000 \mathrm{e}+00$ & $0.000000 \mathrm{e}+00$ & $0.000000 \mathrm{e}+00$ & $0.000000 \mathrm{e}+00$ & $-3.738959 e-06$ & $0.000000 \mathrm{e}+00$ & $0.000000 \mathrm{e}+00$ \\
\hline $\mathrm{S} 1 * \mathrm{RM}$ & $0.000000 \mathrm{e}+00$ & $0.000000 \mathrm{e}+00$ & $0.000000 \mathrm{e}+00$ & $0.000000 \mathrm{e}+00$ & $0.000000 \mathrm{e}+00$ & $0.000000 \mathrm{e}+00$ & $0.000000 \mathrm{e}+00$ \\
\hline S1*AX & $0.000000 \mathrm{e}+00$ & $0.000000 \mathrm{e}+00$ & $0.000000 \mathrm{e}+00$ & $0.000000 \mathrm{e}+00$ & $0.000000 \mathrm{e}+00$ & $0.000000 \mathrm{e}+00$ & $0.000000 \mathrm{e}+00$ \\
\hline S1*T(indep.) & $0.000000 \mathrm{e}+00$ & $0.000000 \mathrm{e}+00$ & $0.000000 \mathrm{e}+00$ & $0.000000 \mathrm{e}+00$ & $0.000000 \mathrm{e}+00$ & $0.000000 \mathrm{e}+00$ & $0.000000 \mathrm{e}+00$ \\
\hline $\mathrm{S} 2 * \mathrm{RM}$ & $0.000000 \mathrm{e}+00$ & $0.000000 \mathrm{e}+00$ & $0.000000 \mathrm{e}+00$ & $0.000000 \mathrm{e}+00$ & $0.000000 \mathrm{e}+00$ & $0.000000 \mathrm{e}+00$ & $0.000000 \mathrm{e}+00$ \\
\hline$S 2 * A X$ & $0.000000 \mathrm{e}+00$ & $0.000000 \mathrm{e}+00$ & $0.000000 \mathrm{e}+00$ & $0.000000 \mathrm{e}+00$ & $0.000000 \mathrm{e}+00$ & $0.000000 \mathrm{e}+00$ & $0.000000 \mathrm{e}+00$ \\
\hline S2*T(indep.) & $0.000000 \mathrm{e}+00$ & $0.000000 \mathrm{e}+00$ & $0.000000 \mathrm{e}+00$ & $0.000000 \mathrm{e}+00$ & $0.000000 \mathrm{e}+00$ & $0.000000 \mathrm{e}+00$ & $0.000000 \mathrm{e}+00$ \\
\hline $\mathrm{RM} * \mathrm{AX}$ & $0.000000 \mathrm{e}+00$ & $0.000000 \mathrm{e}+00$ & $0.000000 \mathrm{e}+00$ & $0.000000 \mathrm{e}+00$ & $0.000000 \mathrm{e}+00$ & $0.000000 \mathrm{e}+00$ & $0.000000 \mathrm{e}+00$ \\
\hline $\mathrm{RM} * \mathrm{~T}$ (indep.) & $0.000000 \mathrm{e}+00$ & $0.000000 \mathrm{e}+00$ & $0.000000 \mathrm{e}+00$ & $0.000000 \mathrm{e}+00$ & $0.000000 \mathrm{e}+00$ & $0.000000 \mathrm{e}+00$ & $0.000000 \mathrm{e}+00$ \\
\hline $\mathrm{AX} * \mathrm{~T}$ (indep.) & $0.000000 \mathrm{e}+00$ & $0.000000 \mathrm{e}+00$ & $0.000000 \mathrm{e}+00$ & $0.000000 \mathrm{e}+00$ & $0.000000 \mathrm{e}+00$ & $0.000000 \mathrm{e}+00$ & $0.000000 \mathrm{e}+00$ \\
\hline & & $\cdots$ & & & & & \\
\hline
\end{tabular}

Fig. 6 Regression coefficient matrix coefficients (only 50 of 127 coefficient rows are shown). 


\begin{tabular}{|c|c|c|c|c|c|c|c|}
\hline LOAD_NAME & N1 & N2 & S1 & S2 & RM & $\mathrm{AX}$ & $T$ (indep.) \\
\hline LOAD_UNIT & lbs & lbs & lbs & lbs & in-lbs & lbs & $\operatorname{deg} \mathrm{F}$ \\
\hline INTERCEPT & $-3.394912 \mathrm{e}-02$ & $1.762373 e+00$ & $-1.054617 e+00$ & $-8.418984 \mathrm{e}-01$ & $-1.579497 e+00$ & $8.546633 \mathrm{e}-01$ & $0.000000 \mathrm{e}+00$ \\
\hline$\cdots[$ [C1INV] & & & & & & & \\
\hline R1 & $2.636071 \mathrm{e}+00$ & $-1.362766 e-01$ & $7.375559 \mathrm{e}-02$ & $-1.046417 e-01$ & $-3.580819 e-01$ & $-1.423766 \mathrm{e}-03$ & $0.000000 \mathrm{e}+00$ \\
\hline R2 & $4.421568 \mathrm{e}-03$ & $2.161605 \mathrm{e}+00$ & $6.843179 \mathrm{e}-03$ & $1.293115 \mathrm{e}-03$ & $9.217462 \mathrm{e}-02$ & $-5.632667 e-05$ & $0.000000 \mathrm{e}+00$ \\
\hline R3 & $4.096360 \mathrm{e}-02$ & $-7.207095 e-01$ & $2.175074 \mathrm{e}+00$ & $-1.070539 \mathrm{e}-01$ & $2.041565 \mathrm{e}-01$ & $5.700654 \mathrm{e}-04$ & $0.000000 \mathrm{e}+00$ \\
\hline R4 & $-7.083644 e-03$ & $-6.194326 e-02$ & $1.559243 \mathrm{e}-02$ & $2.130148 \mathrm{e}+00$ & $-5.172879 e-02$ & $5.209489 \mathrm{e}-04$ & $0.000000 \mathrm{e}+00$ \\
\hline R5 & $-7.506106 e-02$ & $3.149318 \mathrm{e}-01$ & $-4.071820 \mathrm{e}-03$ & $-2.803347 e-01$ & $3.776413 \mathrm{e}+00$ & $-3.702959 e-02$ & $0.000000 \mathrm{e}+00$ \\
\hline R6 & $1.130379 \mathrm{e}-01$ & $-1.711501 \mathrm{e}-01$ & $-2.052633 e-03$ & $-1.426673 e-01$ & $-1.960773 e-02$ & $8.328813 e-01$ & $0.000000 \mathrm{e}+00$ \\
\hline $\mathrm{T}($ dep. $)$ & $2.425852 \mathrm{e}-03$ & $5.367547 \mathrm{e}-02$ & $-3.296893 e-02$ & $-2.052719 e-02$ & $-7.795390 e-02$ & $1.045412 \mathrm{e}-02$ & $1.000000 \mathrm{e}+00$ \\
\hline$\cdot[$ [C1INVC2] & & & ---- & & & ----- & ---- \\
\hline |N1| & $0.000000 \mathrm{e}+00$ & $0.000000 \mathrm{e}+00$ & $0.000000 \mathrm{e}+00$ & $0.000000 \mathrm{e}+00$ & $0.000000 \mathrm{e}+00$ & $0.000000 \mathrm{e}+00$ & $0.000000 \mathrm{e}+00$ \\
\hline |N2 | & $0.000000 \mathrm{e}+00$ & $0.000000 \mathrm{e}+00$ & $0.000000 \mathrm{e}+00$ & $0.000000 \mathrm{e}+00$ & $0.000000 \mathrm{e}+00$ & $0.000000 \mathrm{e}+00$ & $0.000000 \mathrm{e}+00$ \\
\hline |S1| & $0.000000 \mathrm{e}+00$ & $0.000000 \mathrm{e}+00$ & $0.000000 \mathrm{e}+00$ & $0.000000 \mathrm{e}+00$ & $0.000000 \mathrm{e}+00$ & $0.000000 \mathrm{e}+00$ & $0.000000 \mathrm{e}+00$ \\
\hline$|S 2|$ & $0.000000 \mathrm{e}+00$ & $0.000000 \mathrm{e}+00$ & $0.000000 e+00$ & $0.000000 \mathrm{e}+00$ & $0.000000 \mathrm{e}+00$ & $0.000000 \mathrm{e}+00$ & $0.000000 e+00$ \\
\hline |RMI & $0.000000 \mathrm{e}+00$ & $0.000000 \mathrm{e}+00$ & $0.000000 \mathrm{e}+00$ & $0.000000 \mathrm{e}+00$ & $0.000000 \mathrm{e}+00$ & $0.000000 \mathrm{e}+00$ & $0.000000 \mathrm{e}+00$ \\
\hline$|A X|$ & $0.000000 \mathrm{e}+00$ & $0.000000 \mathrm{e}+00$ & $0.000000 e+00$ & $0.000000 \mathrm{e}+00$ & $0.000000 \mathrm{e}+00$ & $0.000000 \mathrm{e}+00$ & $0.000000 \mathrm{e}+00$ \\
\hline $\mid \mathrm{T}($ indep. $) \mid$ & $0.000000 \mathrm{e}+00$ & $0.000000 \mathrm{e}+00$ & $0.000000 \mathrm{e}+00$ & $0.000000 \mathrm{e}+00$ & $0.000000 \mathrm{e}+00$ & $0.000000 \mathrm{e}+00$ & $0.000000 \mathrm{e}+00$ \\
\hline $\mathrm{N} 1 * \mathrm{~N} 1$ & $2.736902 \mathrm{e}-06$ & $2.198676 \mathrm{e}-06$ & $-1.356336 \mathrm{e}-06$ & $1.202792 \mathrm{e}-06$ & $-3.494113 e-06$ & $-1.395175 e-07$ & $0.000000 \mathrm{e}+00$ \\
\hline $\mathrm{N} 2 * \mathrm{~N} 2$ & $6.467866 \mathrm{e}-07$ & $3.866003 e-06$ & $3.908520 \mathrm{e}-08$ & $1.409886 \mathrm{e}-06$ & $8.757922 \mathrm{e}-06$ & $-8.613141 \mathrm{e}-08$ & $0.000000 \mathrm{e}+00$ \\
\hline $\mathrm{S} 1 * \mathrm{~S} 1$ & $-1.026644 \mathrm{e}-08$ & $3.402478 \mathrm{e}-06$ & $1.965330 \mathrm{e}-08$ & $5.585701 \mathrm{e}-07$ & $-5.198494 e-06$ & $55812 e-07$ & $0.000000 \mathrm{e}+00$ \\
\hline $\mathrm{S} 2 * \mathrm{~S} 2$ & $-8.246104 e-07$ & $36 e-06$ & $1.005995 \mathrm{e}-08$ & $2.847495 \mathrm{e}-06$ & $397 e-05$ & $706 e-07$ & $0.000000 \mathrm{e}+00$ \\
\hline $\mathrm{RM} * \mathrm{RM}$ & $1.385228 \mathrm{e}-07$ & $7 e-06$ & $1.705623 \mathrm{e}-08$ & $5136 e-06$ & $579 e-06$ & $5 e-07$ & 0.0000 \\
\hline$A X * A X$ & $0.000000 \mathrm{e}+00$ & $0.000000 \mathrm{e}+00$ & $0.000000 \mathrm{e}+00$ & $0.000000 \mathrm{e}+00$ & $0.000000 \mathrm{e}+00$ & $0.000000 \mathrm{e}+00$ & $0.000000 \mathrm{e}+00$ \\
\hline T(indep.)*T(indep.) & $0.000000 \mathrm{e}+00$ & $0.000000 \mathrm{e}+00$ & $0.000000 \mathrm{e}+00$ & $0.000000 \mathrm{e}+00$ & $0.000000 \mathrm{e}+00$ & $0.000000 \mathrm{e}+00$ & $0.000000 \mathrm{e}+00$ \\
\hline $\mathrm{N} 1 *|\mathrm{~N} 1|$ & $0.000000 \mathrm{e}+00$ & $0.000000 \mathrm{e}+00$ & $0.000000 \mathrm{e}+00$ & $0.000000 \mathrm{e}+00$ & $0.000000 \mathrm{e}+00$ & $0.000000 \mathrm{e}+00$ & $0.0000000+00$ \\
\hline N2*|N2| & $0.000000 \mathrm{e}+00$ & $0.000000 \mathrm{e}+00$ & $0.000000 \mathrm{e}+00$ & $0.000000 \mathrm{e}+00$ & $0.000000 \mathrm{e}+00$ & $0.000000 e+00$ & $0.000000 \mathrm{e}+00$ \\
\hline S1*|S1| & $0.000000 \mathrm{e}+00$ & $0.000000 \mathrm{e}+00$ & $0.000000 \mathrm{e}+00$ & $0.000000 \mathrm{e}+00$ & $0.000000 \mathrm{e}+00$ & $0.000000 \mathrm{e}+00$ & $0.000000 \mathrm{e}+00$ \\
\hline$S 2 *|S 2|$ & $0.000000 \mathrm{e}+00$ & $0.000000 \mathrm{e}+00$ & $0.000000 \mathrm{e}+00$ & $00000 \mathrm{e}+00$ & $0.000000 \mathrm{e}+00$ & $0.000000 \mathrm{e}+00$ & $0.000000 \mathrm{e}+00$ \\
\hline $\mathrm{RM} *|\mathrm{RM}|$ & $0.000000 \mathrm{e}+00$ & $0.000000 \mathrm{e}+00$ & $0.000000 \mathrm{e}+00$ & $0.000000 \mathrm{e}+00$ & $0.000000 \mathrm{e}+00$ & $0.000000 \mathrm{e}+00$ & $0.000000 \mathrm{e}+00$ \\
\hline$A X *|A X|$ & $0.000000 \mathrm{e}+00$ & $0.000000 \mathrm{e}+00$ & $0.000000 \mathrm{e}+00$ & $0.000000 \mathrm{e}+00$ & $0.000000 \mathrm{e}+00$ & $0.000000 \mathrm{e}+00$ & $0.000000 \mathrm{e}+00$ \\
\hline ep.)*|T(indep.) $\mid$ & $0.000000 \mathrm{e}+00$ & $0.000000 \mathrm{e}+00$ & $0.000000 \mathrm{e}+00$ & $0.000000 \mathrm{e}+00$ & $0.000000 \mathrm{e}+00$ & $0.000000 \mathrm{e}+00$ & $0.000000 \mathrm{e}+00$ \\
\hline $\mathrm{N} 1 * \mathrm{~N} 2$ & $3.381583 e-07$ & $-3.784994 e-06$ & $-1.659134 \mathrm{e}-08$ & $-4.371716 e-07$ & $-1.989503 e-07$ & $2.540866 \mathrm{e}-06$ & $0.000000 \mathrm{e}+00$ \\
\hline $\mathrm{N} 1 * \mathrm{~S} 1$ & $0.000000 \mathrm{e}+00$ & $0.000000 \mathrm{e}+00$ & $0.000000 \mathrm{e}+00$ & $0.000000 \mathrm{e}+00$ & $0.000000 \mathrm{e}+00$ & $0.000000 \mathrm{e}+00$ & $0.000000 \mathrm{e}+00$ \\
\hline $\mathrm{N} 1 * \mathrm{~S} 2$ & $0.000000 \mathrm{e}+00$ & $0.000000 e+00$ & $0.000000 \mathrm{e}+00$ & $0.000000 \mathrm{e}+00$ & $0.000000 \mathrm{e}+00$ & $0.000000 \mathrm{e}+00$ & $0.000000 \mathrm{e}+00$ \\
\hline $\mathrm{N} 1 * \mathrm{RM}$ & $0.000000 \mathrm{e}+00$ & $0.000000 \mathrm{e}+00$ & $0.000000 \mathrm{e}+00$ & $0.000000 \mathrm{e}+00$ & $0.000000 e+00$ & $0.000000 \mathrm{e}+00$ & $0.000000 \mathrm{e}+00$ \\
\hline $\mathrm{N} 1 * \mathrm{AX}$ & $0.000000 \mathrm{e}+00$ & $e+00$ & $00000 e+00$ & $00000 e+00$ & $00000 e+00$ & $x e+00$ & $0.000000 \mathrm{e}+00$ \\
\hline N1*T(indep.) & $e+00$ & $e+00$ & $000000 e+00$ & $000 \mathrm{e}+00$ & $00 \mathrm{e}+00$ & $e+00$ & 0.0000 \\
\hline $\mathrm{N} 2 * \mathrm{~S} 1$ & $0.000000 \mathrm{e}+00$ & $0.000000 \mathrm{e}+00$ & $0.000000 \mathrm{e}+00$ & $0.000000 \mathrm{e}+00$ & $0.000000 \mathrm{e}+00$ & $0.000000 \mathrm{e}+00$ & $0.000000 \mathrm{e}+00$ \\
\hline $\mathrm{N} 2 * \mathrm{~S} 2$ & $0.000000 \mathrm{e}+00$ & $0.000000 \mathrm{e}+00$ & $0.000000 \mathrm{e}+00$ & $0.000000 \mathrm{e}+00$ & $0.000000 \mathrm{e}+00$ & $0.000000 \mathrm{e}+00$ & $0.000000 \mathrm{e}+00$ \\
\hline $\mathrm{N} 2 * \mathrm{RM}$ & $0.000000 \mathrm{e}+00$ & $0.000000 \mathrm{e}+00$ & $0.000000 \mathrm{e}+00$ & $0.000000 \mathrm{e}+00$ & $0.000000 \mathrm{e}+00$ & $0.000000 \mathrm{e}+00$ & $0.000000 \mathrm{e}+00$ \\
\hline $\mathrm{N} 2 * \mathrm{AX}$ & $0.000000 \mathrm{e}+00$ & $0.000000 \mathrm{e}+00$ & $0.000000 \mathrm{e}+00$ & $0.000000 \mathrm{e}+00$ & $0.000000 \mathrm{e}+00$ & $0.000000 \mathrm{e}+00$ & $0.000000 \mathrm{e}+00$ \\
\hline N2*T(indep.) & $0.000000 \mathrm{e}+00$ & $0.000000 \mathrm{e}+00$ & $0.000000 e+00$ & $0.000000 \mathrm{e}+00$ & $0.000000 \mathrm{e}+00$ & $0.000000 \mathrm{e}+00$ & $0.000000 \mathrm{e}+00$ \\
\hline $\mathrm{S} 1 * \mathrm{~S} 2$ & $2.806502 \mathrm{e}-07$ & $-1.177517 e-06$ & $1.522437 \mathrm{e}-08$ & $1.048160 \mathrm{e}-06$ & $-1.411985 e-05$ & $1.384521 \mathrm{e}-07$ & $0.000000 \mathrm{e}+00$ \\
\hline $\mathrm{S} 1 * \mathrm{RM}$ & $0.000000 \mathrm{e}+00$ & $0.000000 \mathrm{e}+00$ & $0.000000 \mathrm{e}+00$ & $0.000000 \mathrm{e}+00$ & $0.000000 \mathrm{e}+00$ & $00000 e+00$ & $0.000000 \mathrm{e}+00$ \\
\hline $\mathrm{S} 1 * \mathrm{AX}$ & $0.000000 \mathrm{e}+00$ & $0.000000 \mathrm{e}+00$ & $0.000000 \mathrm{e}+00$ & $0.000000 \mathrm{e}+00$ & $0.000000 \mathrm{e}+00$ & $0.000000 \mathrm{e}+00$ & $0.000000 \mathrm{e}+00$ \\
\hline S1*T(indep.) & $0.000000 \mathrm{e}+00$ & $0.000000 e+00$ & $0.000000 \mathrm{e}+00$ & $0.000000 \mathrm{e}+00$ & $0.000000 \mathrm{e}+00$ & $0.000000 \mathrm{e}+00$ & $0.000000 \mathrm{e}+00$ \\
\hline $\mathrm{S} 2 * \mathrm{RM}$ & $0.000000 \mathrm{e}+00$ & $0.000000 \mathrm{e}+00$ & $0.000000 \mathrm{e}+00$ & $0.000000 \mathrm{e}+00$ & $0.000000 \mathrm{e}+00$ & $0.000000 \mathrm{e}+00$ & $0.000000 \mathrm{e}+00$ \\
\hline $\mathrm{S} 2 * \mathrm{AX}$ & $0.000000 \mathrm{e}+00$ & $0.000000 \mathrm{e}+00$ & $0.000000 \mathrm{e}+00$ & $0.000000 \mathrm{e}+00$ & $0.000000 \mathrm{e}+00$ & $0.000000 \mathrm{e}+00$ & $0.000000 \mathrm{e}+00$ \\
\hline S2*T(indep.) & $0.000000 \mathrm{e}+00$ & $0.000000 e+00$ & $0.000000 \mathrm{e}+00$ & $0.000000 \mathrm{e}+00$ & $0.000000 \mathrm{e}+00$ & $0.000000 \mathrm{e}+00$ & $0.000000 \mathrm{e}+00$ \\
\hline $\mathrm{RM} * \mathrm{AX}$ & $0.000000 \mathrm{e}+00$ & $0.000000 \mathrm{e}+00$ & $0.000000 \mathrm{e}+00$ & $0.000000 \mathrm{e}+00$ & $0.000000 \mathrm{e}+00$ & $0.000000 \mathrm{e}+00$ & $0.000000 \mathrm{e}+00$ \\
\hline RM*T(indep.) & $0.000000 \mathrm{e}+00$ & $0.000000 \mathrm{e}+00$ & $0.000000 \mathrm{e}+00$ & $0.000000 \mathrm{e}+00$ & $0.000000 \mathrm{e}+00$ & $0.000000 \mathrm{e}+00$ & $0.000000 \mathrm{e}+00$ \\
\hline $\mathrm{AX} * \mathrm{~T}$ (indep.) & $0.000000 \mathrm{e}+00$ & $0.000000 \mathrm{e}+00$ & $0.000000 \mathrm{e}+00$ & $0.000000 \mathrm{e}+00$ & $0.000000 \mathrm{e}+00$ & $0.000000 \mathrm{e}+00$ & $0.000000 \mathrm{e}+00$ \\
\hline & & & & & & & \\
\hline
\end{tabular}

Fig. 7 Data reduction matrix coefficients (only 50 of 127 coefficient rows are shown). 

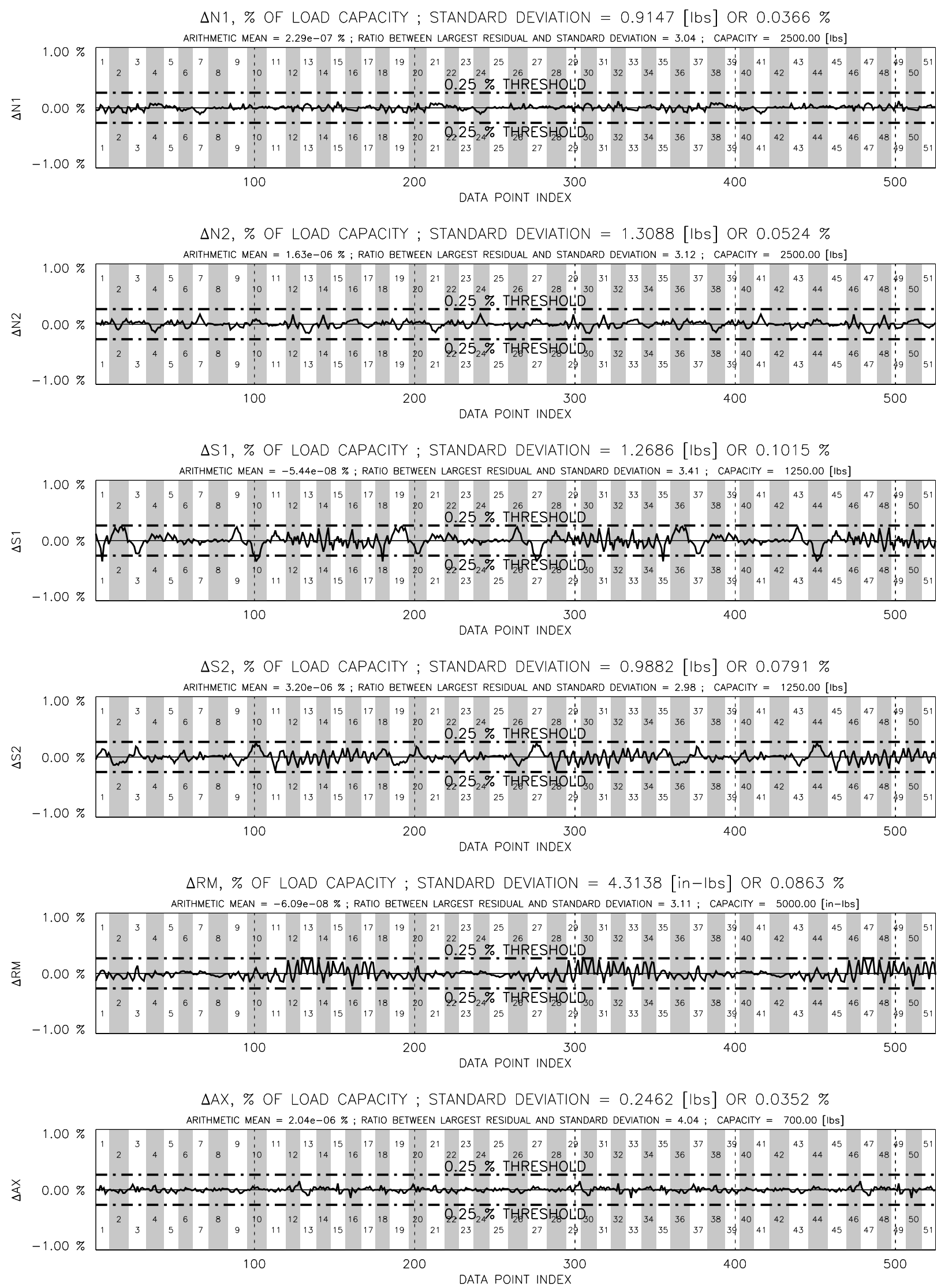

Fig. 8 Computed calibration load residuals versus data point indices.

American Institute of Aeronautics and Astronautics 